\title{
EL CONFLICTO Y EL RIESGO PARA LA VIDA: NIETZSCHE Y FREUD
}

\author{
Conflict and Risk for Life: Nietzsche and Freud
}

Alonso Zengotita, Universidad de Buenos Aires correo electrónico: alonsozengotita@gmail.com

Recepción: 2020/05/18

Aceptación: 2020/08/05

Resumen: Al desarrollar las relaciones en las obras de Nietzsche y Freud, la temática del riesgo y el conflicto no ha sido abordada en profundidad, sino que generalmente se ha tomado como elemento subsidiario para el análisis de otros aspectos. El presente artículo buscará mostrar cómo el modo en que lo vital es pensado en ambos autores se modificará en función de las relaciones que la vida misma guarda - tanto interna como externamenterespecto al riesgo y al conflicto. A partir de esto se marcará un punto de inflexión en donde, en la obra de ambos autores, el conflicto pasa estructuralmente a ocupar el centro mismo de lo vital: la tendencia buscada desde el psicoanálisis en Freud y desde la Wille zur Macht en Nietzsche implicará entonces un empoderamiento del sujeto frente al riesgo inherente que dicha conflictividad supone.

Palabras clave: riesgo, conflicto, vida.

\begin{abstract}
In developing the relationships in the works of Nietzsche and Freud, the theme of risk and conflict has not been addressed in depth, but has generally been taken as a subsidiary element for the analysis of other aspects. This article will seek to show how the way in which the vital is thought of by both authors will be modified according to the relationships that life itself has -both internally and externally- with respect to risk and conflict. From this point on, a point of inflection will be marked where, in the work of both authors, the conflict passes structurally to occupy the very center of what is vital: the tendency seen from the perspective of psychoanalysis in Freud and from Wille zur Macht in Nietzsche will then imply an empowerment of the subject in the face of the inherent risk that such conflict supposes.
\end{abstract}

Keywords: risk, conflict, life. 


\section{Introducción}

Al desarrollar las relaciones en las obras de Nietzsche y Freud, la temática del riesgo y el conflicto no ha sido abordada en profundidad, sino que generalmente ha sido tomada como elemento subsidiario para el análisis de otros aspectos. La articulación Freud-Nietzsche presenta múltiples abordajes en relación a la filosofía, ${ }^{1}$ al concepto de vida, ${ }^{2}$ al poder, ${ }^{3}$ a la psicología, ${ }^{4}$ la literatura y la música, ${ }^{5}$ por hacer mención a algunos. Otros estudios que abordan de manera más integral dicha relación, como los de Ansell-Pearson, Gasser o el clásico de Assoun abordan asimismo dicha temática tangencialmente.

Como objetivo central, el presente artículo buscará mostrar cómo el modo en que lo vital es pensado en ambos autores se modificará en función de las relaciones que la vida guarda - tanto interna como externamente - respecto al riesgo y al conflicto. A partir de esto se marcará un punto estructural de inflexión en donde, en la obra de ambos autores, el conflicto pasa a ocupar el centro mismo de lo vital: la tendencia buscada desde el psicoanálisis, en Freud, y desde la Wille zur Macht, en Nietzsche, implicará entonces un empoderamiento del sujeto frente al riesgo inherente que dicha conflictividad supone.

\footnotetext{
${ }^{1}$ Jean Granier, "Le statut de la philosophie selon Nietzsche et Freud", Nietzsche-Studien, núm. 8 (1979): 210224; Leandro, Drivet, "Freud como lector de Nietzsche. La influencia de Nietzsche en la obra de Freud", Civilizar, 15, núm. 29 (2015): 197-214; Richard Boothby, Freud as Philosopher, -Metapsychology aflter Lacan (London: Routledge, 2001); Adolfo Vázquez Rocca, "La influencia de Nietzsche sobre Freud", Arjé. Revista de Cultura y Ciencias Sociales, núm. 4 (2005): 22-36.

${ }^{2}$ Bernard Reginster, The Affirmation of Life: Nietzsche on Overcoming Nihilism (Cambridge, MA: Harvard University Press, 2006); Adolfo Vázquez Rocca, "Nietzsche y Freud, negociación, culpa y crueldad: las pulsiones y sus destinos, 'eros' y 'thanatos' (agresividad y destructividad)", Eikasia, núm. 57 (2014): 67-97; Darío Uribe, Vitalismo cósmico (Bogotá: Siglo del Hombre, 2002); James Faulkner, "The Body As Text In The Writings of Nietzsche And Freud", Minerva, núm. 6 (2003): 94-124; Rogelio Almeida, Nietzsche e Freud, eterno retorno e compulsão à repetição (São Paulo: Loyola, 2005); Jean Steineger, "Friedrich Nietzsche and Sigmund Freud failure: a tomist protest on truth", Quodlibet Diary, 6, núm. 1 (2004): 23-38.

${ }^{3}$ León Rozitchner, Freud y el problema del poder (México: Folios, 1982); Judith Butler, Mecanismos psíquicos del poder (Madrid: Cátedra, 2010).

${ }^{4}$ Eugenio Fernández García, "En torno al malestar: aproximaciones de Nietzsche y Freud", Mal-Estar Subjetivo, 1, núm. 1 (2001): 10-42; David Chapelle, Nietzsche and psychoanalysis (Albany, NY: State University of New York Press, 1993); Michael Onfray, Nietzsche contra Freud (Madrid: Taurus, 2012); Jacob Golomb, Santaniello y Ronald Lehrer Weaver, Nietzsche and Depth Psychology (New York: State University of New York Press, 1999.

${ }^{5}$ Karl Hanza, "Nec docere neque delectare sed sublimare. Sobre la metáfora de laliteratura como sublimación en Freud y Nietzsche", Estudios de filosofía, núm. 28 (2003): 35-54; Silvia Lévy Lazcano, "Freud y Nietzsche: crónica de un desencuentro", Historia Autónoma, núm. 3, (2013): 63-76.
} 
En función de alcanzar dichos objetivos se producirá, desde un esquema en términos espaciales, el análisis de las relaciones entre vida y riesgo y conflicto — vale decir, el análisis se desplegará en función de los espacios vitales que ocupan el riesgo y el conflicto, y cómo esto decanta estructuralmente en una determinada dinámica vital—.

\section{Nietzsche: despliegue e implosión del espacio metafísico}

El primer libro publicado por Nietzsche —El nacimiento de la tragedia en el espíritu de la música [Die Geburt der Tragödie aus dem Geiste der Musik] de $1872-{ }^{6}$ discurre sobre el nacimiento y fin de la tragedia ática de un modo que colisiona fuertemente con la perspectiva central de su época ${ }^{7}$; allí Nietzsche articula de un modo particular vida y arte: “el arte es la vocación más importante y la actividad esencialmente metafísica de la vida". 8 Esta actividad se despliega desde dos principios: el apolíneo, donde el artista halla la serenidad sostenida en la perfección plástica de la forma, y el dionisíaco, donde la orgía báquica permite que "cada uno se siente no solamente integrado, reconciliado, fundido, sino uno, como si se hubiera desgarrado el velo de Maia y sus pedazos revoloteasen ante la misteriosa Unidad primordial [Ür-eine]". ${ }^{9}$ Combinación de lo apolíneo y dionisíaco, la tragedia antigua es la máxima expresión artística griega. Esta actividad artística encuentra su fundamento en que los griegos

han llegado hasta el fondo de las cosas con mirada decidida [...] Bajo la influencia de la verdad contemplada, el hombre no percibe ya nada más que lo horrible y absurdo de la existencia [...] Y en este peligro inminente de la voluntad, el arte avanza como un dios salvador que trae el bálsamo saludable: él sólo tiene el poder de transmutar ese hastío en imágenes que ayuden a soportar la vida. ${ }^{10}$

\footnotetext{
${ }^{6}$ Reeditado en 1886 con el nombre de El nacimiento de la tragedia o Helenismo y pesimismo (Die Geburt der Tragödie, Oder: Griechentum und Pessimismus).

7 Respecto de la polémica Nietzsche-von Wilamowitz-Möllendorf, $c f r$. William Calder, 'El debate Wilamowitz-Nietzsche: nuevos documentos y una reevaluación', Nietzsche-Studien, n12 (1983): 214-254, como asimismo Dennis Sweet, 'The Birth of 'The Birth of Tragedy", Journal of the History of Ideas, 60 (2) (1999): 345-359.

${ }^{8}$ Friedrich Nietzsche, El nacimiento de la tragedia (Madrid: Alianza, 2007), 22.

${ }^{9}$ Ibid., 28.

${ }^{10}$ Ibid., 56-57.
} 
El arte resulta la actividad fundamental de la vida como herramienta curativa. ${ }^{11}$ En tanto es la existencia misma lo insoportable, el carácter metafísico del arte cobra pleno sentido: la vida ha de proyectarse más allá de su existencia, ha de descentrarse más allá de su carácter físico. La vida halla su redención [Erlösung] al elidir, vía arte, lo sufriente de la existencia. El principio apolíneo "hace ver que el mundo del sufrimiento es necesario para que él, el individuo, se lance a la creación de la visión libertadora y [...] permanezca en calma y lleno de seguridad". ${ }^{12}$ Arte y sufrimiento presentan correspondencia: el arte redime a la vida al librarla del sufrimiento, y éste justifica y es fundamento de la creación artística. El principio dionisíaco postula "la consideración de la individuación como causa primera del mal; el arte, en fin, figurando la esperanza jubilosa de una emancipación del yugo de la individuación y el presentimiento de una unidad restablecida". ${ }^{13}$ La proyección metafísica redime entonces al mal físico y ético. Ahora bien, si emanciparse del mal es liberarse de un yugo y restablecer una unidad, y librarse del sufrimiento permite mantenerse "en calma y lleno de seguridad", entonces la redención que provee el arte a la existencia implica el evitar el conflicto - y el riesgo que éste conlleva-; el arte resulta así una fórmula segura, que no disuelve el sufrimiento, mas lo redime. De modo inverso, el plano de la existencia es conflictivo en tanto sufriente y pleno de divisiones: "Imaginemos por un momento, para una comprensión más justa, estos dos instintos como los dos mundos estéticos diferentes del ensueño y la embriaguez, fenómenos fisiológicos entre los cuales se nota un contraste análogo al uno del otro, al estilo apolíneo y al estilo dionisíaco". ${ }^{14}$

Espacialmente, los instintos actúan en la vida física de modo autorreflexivo, haciendo — vía arte — a la vida del individuo soportable al proyectarlo fuera del plano existencial, ${ }^{15}$ en un más allá apolíneo (más allá de la existencia individual a través de la perfección de la forma) y un más acá dionisíaco (más acá de la existencia individual en la

\footnotetext{
${ }^{11}$ Curación que en tanto implica una proyección respecto del plano existencial, supone asimismo un "impulso fisiológico y psicológico de intoxicación". Kurt Weinberg, "Nietzsche’s Paradox of Tragedy", Yale French Studies, núm. 96 (1999): 87; respecto de la capacidad de intoxicación como transformadora de la percepción en Nietzsche, cfr. Friedrich Nietzsche, Fragmentos póstumos IV (Madrid: Tecnos, 2008), 17[5] 526, 17 [5] 699 y 14 [117] 555, entre otros.

12 Nietzsche, El nacimiento, 38.

13 Ibid., 73.

${ }^{14}$ Ibid., 24.

${ }^{15}$ La tragedia aparece, al combinar ambos procesos, como la máxima redención vital la "suprema consolación metafísica”. Walter Sokel, “On the Dionysian in Nietzsche”, New Literary History, 36, núm. 4 (2005): 502.
} 
desubjetivación del $\ddot{U} r$-Eine). En esta dinámica de desdoblamiento la vida se concibe desde una determinada perspectiva cultural —una determinada definición de lo bueno y lo malo_ articulada a un modo y función específicos del arte.

En Humano, demasiado humano, un libro para pensadores libres [Menschliches, Allzumenschliches. Ein Buch für freie Geister], de 1878, ${ }^{16}$ Nietzsche establece: “[p]orque como quiera que sea, con la religión, el arte y la moral no tocamos la esencia del mundo en sí”, ${ }^{17}$ y, asimismo, "todo lo que les han producido [a los hombres] las hipótesis metafísicas, temibles, agradables, lo que han creado en ellos, es pasión, error y engaño de sí mismos". ${ }^{18}$ Rotundo giro: no sólo el arte ya no detenta el valor esencial/metafísico, sino que la propia metafísica desaparece como vector rector, valioso para la vida. Aquello que en términos culturales proveía el diseño del engrandecimiento vital es ahora nocivo, inútil, debilitante. Algo central, sin embargo, se mantiene: desmontar la carga negativa de la existencia haciéndola más saludable. “¿Sería necesario suponer que la observación psicológica forma parte de los medios de atracción, de salud y alivio de la existencia?". ${ }^{19}$ El fraseo de esta sentencia da cuenta del lugar en el que se ubica la consideración nietzscheana: la duda (¿sería necesario suponer que...?) se relaciona con lo específico de la disciplina psicológica; de lo que ya no hay duda es que sea la disciplina que sea, la misma no puede presentar ya carácter metafísico. ${ }^{20}$

En El nacimiento de la tragedia lo vital presenta dos planos metafísicos que exceden el campo existencial, ${ }^{21}$ produciendo una proyección hacia un más allá apolíneo y un más acá dionisíaco; el arte así resulta esencialmente un procedimiento traslativo. La ruptura de estos planos implica una recentralización de este movimiento: la totalidad de la dinámica pasará ahora por la vida en tanto existencia. Espacialmente, la vida no se

\footnotetext{
${ }^{16}$ En rigor, el primer volumen de Humano, demasiado humano se publica en 1878 , pero es seguido por sus Opiniones y sentencias varias [Vermischte Meinungen und Sprüche] y El caminante y su sombra [Der Wanderer und sein Schatten], de marzo y diciembre de 1879, respectivamente, que son posteriormente publicados en 1886, en un único tomo, como la segunda parte de Humano, demasiado humano.

${ }^{17}$ Friedrich Nietzsche, Humano, demasiado humano (Madrid: Akal, 2007), 20.

${ }^{18}$ Ibid., 19.

${ }^{19} \mathrm{Ibid} ., 40$.

${ }^{20}$ Justamente lo que se observará en el transcurso de las obras nietzscheanas es la multiplicación de las disciplinas no trascendentes: así, puede nombrarse como fisiólogo, psicólogo, médico, químico...

${ }^{21}$ Reiterando la aclaración: el plano de la existencia es aquel del que se buscaba escapar en El nacimiento de la tragedia, según expresa Nietzsche, vía actividades metafísicas.
} 
encuentra ya ni más acá ni más allá sino a la distancia justa: la vida es en el viviente, y esa distancia justa — esa superposición de la vida con la existencia- es el cuerpo. ${ }^{22}$

Los filósofos suelen situarse ante la 'vida' [...] como frente un cuadro que se hubiera pintado de una vez para siempre; [...] no se tiene en cuenta el hecho de que ese cuadro - lo que para nosotros, hombres, se llama actualmente vida y experiencia - ha llegado a ser poco a poco lo que es, e incluso está aun enteramente en su devenir, y por esta razón no puede ser considerado como una dimensión estable. ${ }^{23}$

Espacialmente, la distribución de pesadez para la vida en El nacimiento de la tragedia se hallaba determinada: la vida es una carga en el plano existencial, y su levantamiento se produce a partir de la proyección metafísica; esta distribución implica —usando los términos de Nietzsche - una dimensionalidad estable: no importa el grado de devenir propio de la existencia, en tanto la redención vital remite a otros planos. Por el contrario, con la implosión de los planos metafísicos la vida no es otra cosa que devenir en tanto se halla inmersa en el plano existencial. La dinámica de alivio existencial ya no puede acceder a una trayectoria predeterminada que provea redención. No existe ya un lugar seguro para la vida: la búsqueda del placer y la huida del dolor participan del azar propio del devenir vital, y por ende implican un riesgo y un conflicto inherentes.

Ahora bien, frente a esta dinámica del placer y el dolor, en el escrito de 1882, La ciencia jovial, Nietzsche propone algo distinto:

El odio, las alegrías malvadas, el ansia de rapiña y de dominación y todo lo demás que se llama el mal, forma parte de la extraordinaria economía de la conservación de la especie, economía costosa, pródiga y, en suma, grandemente insensata, pero que es probado que hasta ahora conservó la especie. ${ }^{24}$

No se trata ya de una economía autoconservativa, cuidadosa, que busca dónde encontrar el placer y cómo huir del dolor — es decir, cómo minimizar el riesgo vital — sino de una “economía insensata" que busca dominar y que, por ende, se arriesga.

\footnotetext{
${ }^{22}$ ¿No es el cuerpo central en El nacimiento de la tragedia? Lo es, en tanto sede de los impulsos fisiológicos de la embriaguez y del ensueño; pero a través de ellos, el cuerpo no es sino médium para la traslación hacia lo apolíneo y dionisíaco.

${ }^{23}$ Nietzsche, Humano, 23.

${ }^{24}$ Friedrich Nietzsche, La ciencia jovial (Madrid: Biblioteca Nueva, 2001), 15.
} 
Examinad la vida de los hombres y los pueblos, los mejores y más fecundos, y decidme si un árbol que ha de elevarse orgullosamente al aire se puede librar del mal tiempo y de las tempestades; si la hostilidad y la resistencia del medio exterior y todas las manifestaciones del odio, de la envidia [...] no son circunstancias favorables, sin las cuales sería imposible un grande crecimiento. ${ }^{25}$

Otra economía: maldad y resistencia no para lograr conservación sino crecimiento — para lo cual hay que explícitamente exponerse a lo riesgoso, lo conflictivo-. En Aurora, el aforismo 146: "Nosotros, por el contrario, mediante el sacrificio —en el que estamos incluidos nosotros y el prójimo - elevamos más alto y con más intensidad el sentimiento general del poder humano, suponiendo que no consigamos nada más". ${ }^{26}$ Ahora, el crecimiento del sentimiento de poder vía sacrificio.

Estas múltiples posibilidades dan cuenta de la hesitación nietzscheana, producto de la rotura que la certeza de lo plasmado en El nacimiento de la tragedia proveía; Nietzsche mismo rompe con la seguridad y se abre a un camino de riesgo en su obra; en correspondencia con Peter Gast afirma: “Quiero reservarme para el próximo invierno los libros IX y X; no estoy suficientemente maduro para los pensamientos elementales que pretendo exponer en estos libros". ${ }^{27}$ Dentro de esta variabilidad es posible sin embargo marcar dos certezas: el ámbito vital ya no tiene carácter metafísico, y, por ende, se remite totalmente al plano existencial, lo cual halla su pleno sentido en la sentencia nietzscheana “imprimir el carácter del ser al devenir". ${ }^{28}$ En tanto inmersa en el devenir, la vida no encuentra ya lugares seguros, fijos, en donde se halle aquello que alivie o engrandezca. Pero hay otra certeza —o más bien algo que se convertirá en tal—: cada vez más, como puede apreciarse en los fragmentos citados, la dinámica vital no pasará por evitar el riesgo sino por abrazarlo. El riesgo, y el conflicto que conlleva, es buscado en función de la elevación vital. El tiempo y el espacio de la seguridad han terminado.

\section{Freud: el espacio de la conflictividad enmarcada}

En la obra freudiana, ya en Proyecto para una psicología [Entwurf einer Psychologie] se concibe al flujo energético psíquico en la forma de un circuito que a partir de determinados

\footnotetext{
${ }^{25}$ Ibid., 36, aforismo 19.

${ }^{26}$ Friedrich Nietzsche, Aurora (Barcelona: Alba, 1999), 96, aforismo 146.

${ }^{27}$ Friedrich Nietzsche, Correspondencia VI (octubre 1887-enero 1889) (Madrid: Trotta, 2012), 265.

${ }^{28}$ Nietzsche, Fragmentos, 7 [54], 512.
} 
principios produce su regulación. El primer principio es el de inercia neuronal [neuronalen Trägheit], modelado en términos de la dinámica del arco reflejo, y que busca la descarga energética total a través de la actividad motora. Al existir fuentes continuas e internas de estímulo - lo que será luego nominado como Trieben [pulsiones] — el aparato anímico ha de poder soportar una cierta cantidad energética acumulada, apareciendo el principio de constancia [Konstanzprinzip], que genera la detención parcial de lo que resultaría sino un flujo continuo de descarga. Este principio no contraría sin embargo al anterior: la producción de actividades —como la defensiva - requiere una progresiva complejidad del aparato anímico, con lo cual se necesita suspender la descarga momentáneamente, siendo luego alcanzada de otra manera. Boothby sostiene que aquí ya está presente en su núcleo "la posterior distinción entre el principio del placer, representado por la tendencia original a la descarga inmediata, y el principio de realidad, en el cual la tendencia originaria es modificada bajo la presión de las 'exigencias de la vida". ${ }^{29}$

Estas "exigencias de la vida" 30 se producen en términos de fuentes de estímulo tanto internas como externas. Freud caracteriza hipertróficamente a estas últimas, es decir, presentan una gran potencia respecto a las propias del viviente. Así piensa a la vida en su origen:

[e]sta partícula de sustancia viva flota en medio de un mundo exterior cargado [laden] con las energías más potentes, y sería aniquilada por la acción de los estímulos que parten de él si no estuviese provisto de una protección antiestímulo [Reizschutz]. [...] Para el organismo vivo, la tarea de protegerse contra los estímulos es casi más importante que la de recibirlos. ${ }^{31}$

La potencia de dichas fuerzas es tal que representan un riesgo determinante para el viviente, siendo así la capacidad defensiva fundamental para mantenerse con vida. Una modalidad defensiva particular, la huida, es la que permite establecer una diferenciación patente entre estímulos internos y externos; respecto de la pulsión Freud determina que "[p]uesto que no ataca desde afuera, sino desde el interior del cuerpo, una huida de nada puede valer contra ella". ${ }^{32}$ El fin o meta [Ziel] de una pulsión "es siempre la satisfacción, que sólo puede ser

\footnotetext{
${ }^{29}$ Richard Boothby, Freud as philosopher, Metapsychology aflter Lacan (London: Routledge, 2001), 121.

${ }^{30}$ Sigmund Freud, Proyecto de psicología, en Obras completas, tomo I (Buenos Aires: Amorrortu, 1992), 365.

${ }^{31}$ Sigmund Freud, Más allá del principio del placer, en Obras completas, tomo XVIII, 24.

${ }^{32}$ Sigmund Freud, Pulsiones y destinos de pulsión, en Obras completas, tomo XIV, 114.
} 
alcanzada cancelando el estado de estimulación en la fuente de la pulsión". ${ }^{33}$ En este sentido, Couvreur afirma que "los destinos pulsionales son modos de defensa contra las pulsiones". ${ }^{34}$ Así, tanto los estímulos internos como externos implican peligro, en tanto es necesario ante ellos generar defensas. La conflictividad alcanza al aparato anímico todo: en efecto, Freud se refiere a las distintas disposiciones psíquicas — categorizadas según los tres grandes conjuntos, neurosis, psicosis, perversión - como resultantes de "los conflictos y escisiones producidos en el aparato anímico". ${ }^{35}$ Riesgo y conflictividad son así parte inherente de la dinámica propia del aparato psíquico. ${ }^{36}$ Ahora bien, Freud define a la pulsión como el "concepto límite entre lo anímico y lo somático, como un representante psíquico de los estímulos procedentes del interior del cuerpo, que arriban al alma, y como una magnitud de la exigencia impuesta a lo anímico a consecuencia de su relación con lo somático". ${ }^{37}$ En términos de dicha relación la conflictividad no queda enmarcada solamente en lo psíquico. Las pulsiones mismas presentan oposición y conflicto entre sí, como marca Freud al referirse a las representaciones asociadas a la perturbación psicógena de la vista.

[L]as oposiciones entre representaciones no son sino la expresión de las luchas entre las pulsiones singulares. De particularísimo valor para nuestro ensayo explicativo es la inequívoca oposición entre las pulsiones que sirven a la sexualidad, la ganancia de placer sexual y aquellas otras que tienen por meta la autoconservación del individuo, las pulsiones yoicas. ${ }^{38}$

En los ciegos histéricos, dirá Freud, la ceguera es tal para la conciencia: las representaciones asociadas a las pulsiones yoicas han sido expulsadas por aquellas asociadas a las pulsiones sexuales. Así, en función de la relación psique/soma el cuerpo mismo es campo de batalla de las pulsiones.

\footnotetext{
${ }^{33}$ Ibidem.

${ }^{34}$ Catherine Couvreur, "Une équation à deux inconnues", Revue Française de Psychanalyse, 'La pulsion de mort', tomo III (marzo-abril, 1989): 658.

${ }^{35}$ Freud, Más allá, 10.

${ }^{36}$ En El yo y el ello [Das Ich und das Es] Freud da cuenta de modo esquemático —es decir, en términos generales - de las interacciones conflictivas entre las diversas partes que hacen a la dinámica del aparato psíquico — el ello, el yo, el superyó y la realidad objetiva — donde se da cuenta de las "servidumbres del yo" respecto a la permanente labor de resolución de conflictos que el exterior y las demás instancias psíquicas implican para el viviente como todo.

${ }^{37}$ Freud, Pulsiones, 115.

38 Sigmund Freud, "La perturbación psicógena de la visión según el psicoanálisis", en Obras completas, tomo XI, 211.
} 
Espacialmente, la conflictividad acapara al aparato psíquico como un todo, expandiéndose asimismo al cuerpo. Ahora bien, ¿qué tanto del cuerpo? En Tres ensayos para una teoría sexual [Drei Abhandlungen zur Sexualtheorie] (1905), Freud despliega su concepción de sexualidad, enfrentándola a "la opinión popular" que sostiene que la misma

[f]altaría en la infancia, advendría en la época de la pubertad y en conexión con el proceso de maduración que sobreviene en ella, se exteriorizaría en las manifestaciones de atracción irrefrenable que un sexo ejerce sobre el otro, y su meta sería la unión sexual o, al menos, las acciones que apuntan en esa dirección. ${ }^{39}$

Frente al carácter acotado que la misma presenta en términos tanto de despliegue como de temporalidad, la concepción freudiana presenta una eminente ampliación, partiendo desde la calificación del infante en cuanto a su sexualidad en términos de "perverso polimorfo", es decir, que el punto de anclaje corporal a partir del cual el infante obtiene satisfacción sexual no se halla fijo, sino que es variable. De este modo, no sólo en términos temporales sino también en términos de espacialidad corporal se produce una expansión del campo sexual: ya no un área específica, sino que la totalidad del cuerpo es campo de posible acción sexual.

Esta capacidad perversa de variación se despliega en múltiples registros vitales: ${ }^{40}$ la sexualidad ya no abarca solamente aquello definido a partir del fin sexual normal, o de las diversas variaciones perversas, sino que la capacidad de satisfacción puede tomar parte en procesos patógenos, sin desmedro de presentar, para el individuo involucrado en dicho proceso, una alta cuota de sufrimiento, pero asimismo conforma de modo fundamental actividades esenciales para el proceso civilizatorio ligadas al arte, la ciencia, la moral e incluso a la religión. ${ }^{41}$ La totalidad de las actividades humanas parecen así hallarse articuladas a esta capacidad de variabilidad perversa de lo sexual. ${ }^{42}$ Espacialmente, el carácter de perversión, que implica conflicto en tanto ruptura de "normalidad", recubre la totalidad de las actividades humanas.

\footnotetext{
${ }^{39} \mathrm{Ibid}$., Tres ensayos de teoría sexual, en Obras completas, tomo VII, 123.

${ }^{40}$ Como Brenner señala, "Sobre lo que Freud quería llamar la atención al hablar de Trieb en vez de Instinkt, yo creo, es que el comportamiento sexual humano está caracterizado por ser cualquier cosa menos estereotipado, como lo evidencia el comportamiento sexual de los niños, las fantasías sexuales y los síntomas neuróticos, y la variedad de perversiones sexuales". Charles Brenner, "Aspects of Psychoanalytic Theory: Drives, Defence and the Pleasure-Unpleasure Principle", Psychoanalytic Quarterly, 77 (2008): 708.

${ }^{41}$ Cfr. Sigmund Freud, Tótem y tabú, El malestar en la cultura, El porqué de la guerra, entre otros.

${ }^{42}$ Capacidad que Lacan sostendrá como fundamental, al caracterizar a la sublimación como paradigma de la satisfacción sexual. Cfr. Jaques Lacan, "Clase 12: la sexualidad en los desfiladeros del significante", Seminario XI, (Madrid: Paidós, 2003).
} 
Ahora bien, este despliegue halla a nivel psíquico un regulador princeps: el principio del placer.

En la teoría psicoanalítica adoptamos sin reservas el supuesto de que el decurso de los procesos anímicos es regulado automáticamente por el principio de placer. Vale decir, creemos que en todos los casos lo pone en marcha una tensión displacentera, y después adopta tal orientación que su resultado final coincide con una disminución de aquella, esto es, con una evitación de displacer o una producción de placer. ${ }^{43}$

El placer es concebido entonces en términos de disminución energética — baja de tensióny el displacer como aumento. ${ }^{44}$ La disminución del displacer se halla asociada a una disminución de las perturbaciones energéticas, que como tales implican conflicto: tanto interna como externamente, la intrusión de fuerzas busca ser disminuida, y, por ende, lo conflictivo solucionado. ${ }^{45}$ Hacia dentro del aparato psíquico, el conflicto está enmarcado por esta tendencia universal ordenadora del principio del placer.

\section{Nietzsche y Freud: el conflicto en el centro de la vida}

En Así habló Zarathustra, un libro para todos y para ninguno [Also Sprach Zarathustra. Ein Buch für Alle und Keinen], ${ }^{46}$ Nietzsche parece haber trazado para el hombre un camino vital determinado:

El hombre es una cuerda tendida entre la bestia y el Superhombre: una cuerda sobre un abismo.

Un peligroso ir más allá, un peligroso detenerse, un peligroso volver hacia atrás, un vacilar peligroso y un peligroso estar de pie.

\footnotetext{
${ }^{43}$ Freud, Más allá, 7. El principio del placer entonces "se deriva del principio de constancia" siendo concebido este último en términos de que "el aparato anímico se afana por mantener lo más baja posible, o al menos constante, la cantidad de excitación presente en él". Ibid., 9.

${ }^{44}$ Esto no es del todo exacto; como da cuenta Freud mismo, existen situaciones en las cuales el aumento de tensión se halla asociado a un aumento del placer, por lo que concluye que "el factor decisivo respecto de la sensación es, probablemente, la medida del incremento o reducción en un periodo de tiempo", sin embargo, "no es aconsejable adentrarnos más en este problema hasta que observaciones bien precisas puedan servirnos de guía". Ibid., 8.

${ }^{45}$ En este mismo sentido se puede comprender al síntoma como formación de compromiso entre instancias psíquicas en conflicto: la solución no implica una abolición de dicho conflicto, sino la tendencia por parte del aparato psíquico, regido por el principio del placer, a mantener lo cuantitativamente disruptivo a un mínimo. ${ }^{46}$ Las dos primeras partes del libro son de 1883; la tercera es de 1884, y la cuarta y última, de 1885.
} 
Lo más grande del hombre es que es un puente y no una meta. Lo que debemos amar en el hombre es que consiste en un tránsito y un ocaso. ${ }^{47}$

El hombre ha de vivir una vida de peligro y sufrimiento en orden de superar la especie humana: "i[s]ea vuestro mismo mandar un obedecer! [...] ¡Vivid pues, vuestra vida de obediencia y de guerra! ¿Qué importa vivir mucho tiempo? ¿Qué guerrero quiere ser tratado con indulgencia?". ${ }^{48}$ El hombre de virtudes guerreras, el que manda, obedece al mandato del tránsito: su vida importa en tanto es preparación para el Übermensch, es decir, en tanto soporta la dureza y no busca preservarse. En esta economía del riesgo y el sacrificio la vida adquiere una dinámica determinada. "Este secreto me ha revelado la vida: "Mira -me vino a decir- yo soy lo que siempre debe superarse a sí mismo"”. ${ }^{49}$ La autoconservación de Humano, demasiado humano vía búsqueda del placer y evitación del dolor ha sido abandonada definitivamente; el crecimiento no es en pos de la conservación, como en La ciencia jovial, y no se busca tampoco el crecimiento del sentimiento de poder, como en Aurora, sino el crecimiento del poder mismo: "[s]olamente hay voluntad allí donde hay vida: pero no voluntad de vida, sino — tal es mi doctrina - ¡voluntad de poder!". ${ }^{50}$ La vida no busca la conservación o el placer; el devenir vital vale en tanto hay autosuperación [Selbstüberwindung] en pos del poder: la vida como Wille zur Macht.

La meta que es el Übermensch no reaparece en los escritos nietzscheanos posteriores a Zarathustra, sino hasta unas breves menciones en Ecce Homo (1888), en las cuales el carácter de superación y meta última de la especie humana parece hallarse bastante atenuado, sino elidido:

El término 'superhombre', que designa a un tipo de óptima constitución, en contraste con los hombres 'modernos', en contraste con los hombres 'buenos', con los cristianos y demás nihilistas.' Ya sea porque se trata de un proyecto de muy largo plazo, por lo cual la tarea presente es la de preparar — desde el hombre - la llegada del Übermensch, ya sea porque esa meta ha sido abandonada como tal en algún grado, el campo de estudio en el que vuelven a volcarse las reflexiones nietzscheanas es el del hombre. 'No es mi problema qué

\footnotetext{
${ }^{47}$ Friedrich Nietzsche, Así habló Zarathustra (Madrid: Alianza, 2007), 36. Tránsito — Übergang—, proviene de Übergehen, traducible como "pasar al otro lado", y también "transitar". Übergang, así, adquiere el sentido de "pasar (a ser) otra cosa": el Übermensch.

${ }^{48}$ Ibid., 65.

${ }^{49}$ Ibid., 136.

${ }^{50}$ Ibid., 172.
} 
reemplazará al ser humano: sino qué tipo de humano se debe elegir, se debe querer, se debe criar como tipo más valioso. ${ }^{51}$

En tres libros posteriores a Zarathustra —Más allá del bien y del mal, preludio a una filosofía del futuro [Jenseits von Gut und Böse. Vorspiel eine Pilosophie der Zukunft] (1886), La genealogía de la moral, un escrito polémico [Zur Genealogie der Moral. Eine Streitschrift] (1887), y El ocaso de los ídolos, o cómo se filosofa a martillazos [GötzenDämmerung, oder: Wie man mit dem Hammer philosophirt] (1889)—52 se vuelve sobre temas críticos: el peligro del cristianismo, la generación de valores, el trasmundo como debilitante, el papel de la razón; en este marco crítico se despliega una variedad de tipos vitales —el aristócrata, el enfermo, el asceta, el espiritual - a partir de la vida como Wille zur Macht. Ahora bien, este mismo concepto presenta modificaciones: ya no "solamente hay voluntad allí donde hay vida", sino que la noción de voluntad de poder se expande a otros espacios: la vida no orgánica, ${ }^{53}$ el plano orgánico-tisular, ${ }^{54}$ lo no vital mismo. ${ }^{55}$

En tanto disposición colectora de las fuerzas vitales pensadas en términos de voluntad de poder la figura del Übermensch actuaba como un poderosísimo polo atractivo, encauzando una continuidad económica sacrificial, direccionando el conflicto: el hombre, el pueblo elegido - los superiores_-, el Übermensch. Lateralizada esa meta en la cual el devenir humano se hallaba determinado como un medio, la Wille Zur Macht parece desdibujar sus contornos específicos y desbordar su cauce. En términos espaciales, si a través de Humano, demasiado humano se produce la implosión de los planos metafísicos, para quedar la vida a través de su camino por Aurora y La ciencia jovial contenida en el plano del devenir existencial y, finalmente, quedar fijada en una fórmula vital — aquella de la meta desplegada por Zarathustra-, se asiste ahora a un nuevo despliegue, una nueva variabilidad. Como en El nacimiento de la tragedia, se produce un más acá y un más allá:

\footnotetext{
${ }^{51}$ Nietzsche, Fragmentos, 11[413], 490.

52 Este último libro no es publicado bajo la supervisión de Nietzsche, quien a esa altura se hallaba imposibilitado, sino por Peter Gast y Overbeck.

53 “Tomemos el caso más simple, el de la nutrición primitiva: el protoplasma extiende sus pseudópodos para buscar algo que se le resiste -no por hambre, sino por voluntad de poder". Nietzsche, Fragmentos, 14 [174], 595-596.

54 " [e]l organismo entero, hasta la edad de la pubertad, es un tal complejo de sistemas que luchan por el crecimiento de sentimientos de poder". Ibid., 14 [174], 596.

55 "La voluntad de acumular fuerza [...] ¿No deberíamos tener el derecho de admitir esa voluntad como causa motora incluso de la química? ¿Y en el orden cósmico?”. Ibid., 14 [81], 535.
} 
la Wille zur Macht se expande más allá de lo orgánico hacia lo inorgánico y se proyecta más acá de la vida del individuo, hacia el órgano y hacia la vida no orgánica. Sin embargo, la dinámica de expansión cualitativa —en tanto no metafísica — resulta la inversa: si en $\mathrm{El}$ nacimiento de la tragedia ese movimiento hacia otros planos de la existencia implicaba un alejamiento de lo sufriente, del conflicto, del dolor, en la expansión propia de la vida como Wille zur Macht es el aspecto de la lucha de fuerzas, del conflicto y del riesgo el que perpetra una dinámica ascendente.

Si tomando al hombre como eje se considera esa Wille zur Macht que desborda el cauce marcado en Zarathustra, se obtiene una expansión de tipo vertical que va hacia un más allá — lo inorgánico — y un más acá —el tejido, el órgano, la vida no orgánica—. Sin embargo, se produce asimismo una expansión de tipo horizontal: como se marcó anteriormente, se presenta una multiplicidad de tipologías, en la forma de diversas modalidades de vida humana en relación a la voluntad de poder: el enfermo, el asceta, el aristócrata, el espiritual, el malvado, la "bestia rubia". ${ }^{6}$ En términos espaciales, expandiéndose a través de estos ejes la dinámica conflictiva de la Wille zur Macht logra recubrir la totalidad del plano existencial, escapando a la direccionalidad impuesta por el Übermensch.

Freud ubicará la ruptura con la determinación del principio del placer justamente en un Más allá del principio del placer [Jenseits des Lustprinzips] desde el aparecer en términos clínicos de la compulsión de repetición [Wiederholungszuang], la cual provee de vivencias "que no contienen posibilidad alguna de placer"s7 e implican "tendencias que

\footnotetext{
${ }^{56}$ Así, en Más allá del bien y del mal se da cuenta del tipo del filósofo (c fr. "Sección primera: de los prejuicios de los filósofos"), del científico ("Sección sexta: nosotros los doctos"), del sacerdote ("Sección tercera: el ser religioso"), y, asimismo, del tipo aristocrático (“Sección novena: ¿qué es aristocrático?”). En el tratado primero de La genealogía de la moral aparecen los tipos del bueno y el malvado, y aquel de la mala conciencia y el enfermo en el segundo; el tipo fisiológico del asceta hace su aparición en el tercero. En "El problema de Sócrates", apartado de El ocaso de los ídolos, se retoma la temática del tipo de vida descendente que representa Sócrates - ya abordado en El origen de la tragedia - ; asimismo se da cuenta del declive vital al que la moral moderna ha llevado al hombre, en "Los que quieren hacer mejor a la humanidad". Finalmente, numerosos fragmentos póstumos de la época dan cuenta de esta variedad tipológica: $\mathrm{c} f r$. NF, 14 [178], 14 [179], sobre la práctica cristiana y el ascetismo; 1 [123], [202], [235], 5 [50], [89], sobre los hombres superiores y los aristócratas; 2 [10], [13], respecto al hombre democrático; 9 [5], sobre las tipologías de genio europeas; 10 [17], [39], sobre los hombres de rebaño, entre otros.

${ }^{57}$ Freud, Más allá, 20. Como marca Freud, el principio de realidad da unos rodeos impuestos por exigencias externas, pero se busca igualmente en último término la descarga energética; el displacer que implican ciertos conflictos psíquicos — dando como ejemplo los neuróticos — no niega tampoco al principio del placer: lo que
} 
serían más originarias que el principio del placer e independientes de él". ${ }^{58}$ Ahora bien, dichas tendencias no representan simplemente aspectos parciales de la vida anímica, que se colocan de modo anterior al principio del placer; en tanto las propias pulsiones como tendencias vitales fundamentales se hallan definidas a partir del carácter de compulsión de repetición, la totalidad del campo vital pasa a ser concebido a partir de un más allá de la regulación del placer. Al lateralizar la relevancia del principio del placer como regulador económico vital, el carácter de conflicto e imbricación pulsional se proyecta al primer plano en términos de un más fundamental devenir de la vida.

Ahora bien ¿supone esto una modificación total del manejo energético vital? El concepto de "más allá" [Jenseits] marca lo contrario: no se trata del pasaje neto de un modelo de la determinación del flujo energético a una modalidad de la pura conflictividad, sino de una reconfiguración del modo de interrelación de dichas modalidades. El establecimiento de un más allá respecto del Lustprinzip supone la remoción del mismo —y de su modificación, el principio de realidad - en términos de regulador económico general, dando paso a un carácter pulsional dinámico no en tanto universal —y así, no produciendo un reemplazo en términos de principio - sino eminentemente en tanto conflictivo. Dicho de otro modo, son dos ahora los espacios en que el despliegue de la dinámica del aparato psíquico es posible: el más acá y el más allá del principio del placer. La ruptura entonces supone no el reemplazo de un principio por otro, sino el quiebre de la determinación misma que la universalidad del principio implica. Estructuralmente, se asiste entonces a la centralidad de la conflictividad — como la no existencia de una determinación prevalente única - respecto a la dinámica vital.

Esta centralidad del conflicto implica una expansión en términos espaciales justamente, se trata de un más allá - hacia dentro del aparato psíquico: si el principio del placer enmarcaba la extensión posible de la dinámica psíquica, se abre ahora un espacio más allá, de "nada de placer para ninguna instancia psíquica", un espacio desplegado en otras coordenadas. Ahora bien, esta disposición no implica solamente una expansión hacia dentro del aparato psíquico, sino también una más allá del mismo: "la lucha entre Eros y

es sentido como displacer por una instancia psíquica es sentido como placer por otra. Así, el imperio del principio del placer se sostiene en estos escenarios.

${ }^{58}$ Freud, Más allá, 17. 
Muerte [...] Esta lucha es el contenido esencial de la vida en general [...]". ${ }^{59}$ La concepción del conflicto en términos de pulsiones de vida [Lebenstriebe] y pulsiones de muerte [Todestriebe] se expande al plano de la vida en su totalidad, a todo lo animado.

En términos de estructura espacial, hacia dentro de las obras de Freud y Nietzsche el principio del placer y el Übermench cumplen roles isomórficos: establecen un encuadre en términos dinámicos direccionando, correspondientemente, el conflicto del aparato psíquico y de la vida del hombre. Es sólo cuando se rompe con dicha determinación que se producen las expansiones del conflicto, y estructuralmente la conflictividad cobra el rol central para la vida. Así, la Wille zur Macht se expande a todo el plano de lo vivo, e incluso busca pensar también el plano de lo inanimado; la conflictividad pulsional en Freud excede los límites del principio del placer y asimismo los del aparato psíquico para extenderse sobre el plano de lo animado en general. Ahora bien, ¿cómo es concebido ese conflicto?, y, sobre todo, ¿qué se puede hacer con él?

\section{Conflicto y riesgo, dominio y empoderamiento}

Nietzsche plantea de un modo específico al conflicto de las fuerzas hacia dentro del viviente:

La contraposición de las pasiones, la duplicidad, la triplicidad, la multiplicidad de las 'almas en un único pecho':60 muy insano, ruina interna, disgregante, delatando e intensificando una disensión y un anarquismo internos: a no ser que una pasión finalmente acabe por dominar. Retorno de la salud. ${ }^{61}$

Este dominio [Bewältigung] ¿implica la desaparición de las diferencias de fuerzas?

La pasión dominante, la cual lleva consigo incluso la forma suprema de la salud en general: aquí se alcanza de manera óptima la coordinación de los sistemas internos y el concurso de sus trabajos al servicio de una unidad - pero, ¡ esto es prácticamente la definición de la salud! ${ }^{62}$

\footnotetext{
${ }^{59}$ Sigmund Freud, El malestar en la cultura, en Obras completas, tomo XXI, 118.

${ }^{60}$ Alusión al libro I de Fausto, de Goethe.

${ }^{61}$ Nietzsche, Fragmentos, 14 [157], 584.

${ }^{62}$ Ibid., 14 [158], 584.
} 
El dominio de una pasión — de una fuerza - implica no el borramiento sino la coordinación de las múltiples fuerzas en una dirección y sentido determinados —en una perspectiva impuesta hacia dentro del viviente - ${ }^{63}$ lo cual representa el epítome de la vida saludable, ascendente.

En El yo y el ello (1923), Freud aborda las relaciones entre las distintas instancias psíquicas y la realidad objetiva. Entre otros temas, desarrolla los "vasallajes del yo" como "pobre cosa sometida a tres servidumbres $-\mathrm{y}$ que en consecuencia sufre las amenazas de tres clases de peligros: de parte del mundo exterior, de la libido del ello y de la severidad del superyó". ${ }^{64} \mathrm{El}$ yo ha de mediar entre los requerimientos energéticos y los peligros que suponen para la integridad del viviente estas tres instancias; la labor y conflicto constante que esto implica lo pone como "pobre cosa". Pero respecto a esta situación es que aparece el psicoanálisis como instrumento transformador del conflicto en una dirección y sentido determinados; el mismo tiene el "propósito de sustituir las represiones permeables por unos dominios confiables y acordes al yo". ${ }^{65}$ Este tipo de dominio [Bewältigung] se da en términos de que "un análisis debe producir un estado que nunca preexistió de manera espontánea en el interior del yo y cuya neo-creación [neu schöpfung], creación de un estado que no preexistía, constituye la diferencia esencial entre un hombre analizado y no analizado". ${ }^{6}$

Esta labor psicoanalítica que supone fortalecer al yo frente a las imposiciones, conflictos y peligros que le implican sus funciones, es una producción más allá del principio del placer. En efecto, al respecto Freud escribe:

Por el lado del paciente, actúan con eficacia a favor nuestro algunos factores ajustados a la ratio, como la necesidad de curarse motivada en su padecer y el interés intelectual que hemos podido despertarle hacia las doctrinas y revelaciones del psicoanálisis, pero, con

\footnotetext{
${ }^{63} \mathrm{Y}$ de este modo son consideradas asimismo las culturas ascendentes, como por ejemplo la griega: 'Hay allí un subyugar la plenitud de lo viviente, la medida se vuelve dominante, a la base está esa calma del alma fuerte que se mueve con lentitud y tiene aversión a lo demasiado vivaz. Se honra y se eleva el caso general, la ley; la excepción, por el contrario, es dejada de lado; el matiz, borrado. Lo firme, poderoso, sólido, la vida que reposa extendida y potente -eso 'gusta' [...]'. Ibid., 9 [151], 282.

${ }^{64}$ Sigmund Freud, El yo y el ello, en Obras completas, tomo XIX, 56.

65 Sigmund Freud, "Análisis terminable e interminable", en Obras completas, tomo XXIII, 232. La represión [Verdrängung] resulta el estado al que llega una moción pulsional al "chocar con resistencias que quieran hacerla inoperante". Freud, Pulsiones, 141. En tanto la particular satisfacción pulsional resulta inconciliable respecto de otras exigencias, y por ende resulta rechazada de la conciencia y mantenida alejada de ella. Como Freud, establece, esto es lo que el psicoanálisis busca deshacer en términos de dominio acorde al yo.

${ }^{66}$ Freud, "Análisis terminable", 229.
} 
fuerzas mucho más potentes, la transferencia positiva con que nos solicita. Por otra parte, pugnan contra nosotros la transferencia negativa, la resistencia de represión del yo (vale decir, su displacer de exponerse al difícil trabajo que se le propone), el sentimiento de culpa oriundo de la relación con el superyó y la necesidad de estar enfermo anclada en unas profundas alteraciones de su economía pulsional. ${ }^{67}$

Desmontar las represiones venciendo las resistencias supone una dinámica conflictiva en la que necesariamente se juegan múltiples instancias displacenteras, y, por ende, no sostenida en el contexto del principio del placer. ${ }^{68}$ Según Freud “el psicoanálisis es un instrumento destinado a posibilitar al yo la progresiva conquista del ello". ${ }^{9}$ A la manera nietzscheana, se busca imponer una determinada perspectiva - yoica en el caso del psicoanálisis — en una dinámica de dominio. ${ }^{70}$ Dicha dinámica implica en Nietzsche una coordinación de las fuerzas y sistemas del viviente en una determinada dirección y sentido; como en Freud, no se produce una desaparición de la multiplicidad de fuerzas e instancias — es decir, no hay desaparición de la diferencia_-, sino una reconducción determinada de las mismas. En este sentido, la tendencia a la vida ascendente nietzscheana es asimilable — vía dominio [Bewältigung] — a la neo-creación como objetivo del psicoanálisis.

Espacialmente, se halla asimismo un despliegue similar en las posturas de Nietzsche y Freud. En el plano de la interioridad del viviente lo que se produce es la generación de dominio. En Nietzsche, en vez de tratarse de múltiples sistemas y fuerzas en anarquía, divididos, cada vez más partes del viviente quedan puestas bajo la dirección de una determinada perspectiva, siendo la salud óptima aquella donde se alcanza la "total

${ }^{67}$ Ibid., 181.

${ }^{68}$ Puede replicarse, el principio de realidad también permite instancias displacenteras, y sin embargo se halla enmarcado en el principio del placer. Lo está, pero en cuanto a su fin, es decir, su meta final es lograr la descarga energética, sólo aplazada brevemente. Como se marcó, la finalidad de la práctica psicoanalítica no será la de buscar placer, esto podrá ser — y se remarca, sólo en términos de posibilidad - un efecto lateral, sino la de lograr un tipo específico de dominio [Bewältigung].

${ }^{69}$ Freud, El yo y el ello, 56. Respecto de la no referencia al superyó en esta sentencia, cabe señalar que a lo largo de este texto Freud estipula la íntima relación entre las fuerzas del ello y las superyoicas; vale decir, dominar [bewältigen] al ello implicaría a su vez un dominio respecto al superyó.

${ }^{70}$ Esto ha de ser entendido en términos de tendencia, justamente por eso habla Freud de "progresiva conquista"; asimismo, en el caso nietzscheano la salud es "óptima" cuando se logra la regulación total de las fuerzas bajo una perspectiva -pero como Nietzsche mismo proclama, el logro de dicha "gran salud" [Große Gesundheit] es tarea de siglos, orientada en términos de polo por la figura del Übermensch (cfr. Así habló Zarathustra, especialmente 'Prólogo de Zarathustra', 36; 'Del hombre superior', 385; 'De la superación de sí mismo', 136, entre otros). Hay así en ambos casos un sentido determinado de la progresividad del dominio: en Nietzsche, el privilegio de las fuerzas activas por sobre las reactivas, en función de una vida ascendente; en Freud, un fortalecimiento del yo respecto de las otras instancias psíquicas. 
coordinación" del viviente bajo una fuerza directriz. En Freud, el objetivo psicoanalítico es la progresiva conquista del ello por el yo. Esta progresión del viviente encuentra su correlativo en la relación que el mismo presenta hacia el exterior. Según Nietzsche, la vida ascendente es "voluntad de poder que, desde el interior, somete e incorpora a sí cada vez más 'exterior"" ${ }^{71}$ En Freud, la obtención de objetivos psicoanalíticos implica una modificación de las relaciones del sujeto con la realidad exterior; diversas categorizaciones psíquicas — fobias, histerias, neurosis, etc.- hallan asociados múltiples impedimentos e inhibiciones ${ }^{72}$ modificaciones en las primeras implican cambios en los segundos.

Tanto en Nietzsche como en Freud, en un momento determinado de su obra el conflicto pasa a ocupar el lugar de dinámica central para la vida. En Nietzsche este desplazamiento estructural comienza al abandonar la dinámica propia de El nacimiento de la tragedia, no quedando más que el plano existencial para el despliegue vital, con todo su riesgo y conflictividad. De allí en adelante Nietzsche habrá de considerar diversas formulaciones de la dinámica vital, arribando a la determinación dada en el Zarathustra a partir del Übermensch. En este punto, estructuralmente se halla en una instancia similar a la del imperio del principio del placer: ${ }^{73}$ el conflicto en su conjunto es específicamente direccionado. El desplazamiento estructural, así, es completado al momento en que dicha determinación desaparece: dejado de lado el Übermesch como foco de la dinámica vital, se asiste a una progresiva expansión de la Wille zur Macht a la totalidad de la existencia. Espacialmente se asiste a una dinámica de contracción y expansión: la concentración de la vida en el plano de la existencia, contraída aún más en función de la focalización producto del Übermench como meta, expandiéndose luego por la totalidad del plano existencial en términos de Wille zur Macht.

En Freud el punto de inflexión aparece con el más allá del principio del placer: la conflictividad deja de estar enmarcada por ese principio ordenador para encontrarse en su

\footnotetext{
${ }^{71}$ Nietzsche, Fragmentos, 7 [9], 211.

${ }^{72}$ Así, la equinofobia de Juanito supone una concreta limitación de movimiento, por supuesto no sólo esto, pero respecto de la espacialidad en función de la realidad exterior es lo que aquí interesa remarcar. ( $c f r$. Sigmund Freud, Análisis de la fobia de un niño de cinco años, en Obras completas, tomo X).

${ }^{73}$ Por supuesto, la tendencia que implica cada uno resulta diversa, incluso inversa: mientras que el principio del placer tiende a la reducción del estímulo, el polo vital que implica el Übermensch busca cada vez más lucha y sacrificio. Pero el análisis aquí desplegado es en función no de las tendencias sino de la estructura misma que implican tanto el principio del placer como el Übermensch en términos de dinámica vital.
} 
despliegue en el centro de la vida: "la lucha entre Eros y Muerte [...] Esta lucha es el contenido esencial de la vida en general [...]". ${ }^{74}$ Lo esencial de la vida pasa por el conflicto; el psicoanálisis mismo como práctica pasa a ubicarse más allá del principio del placer. Espacialmente, al desplegar a la dinámica del aparato psíquico más allá de las fronteras del principio del placer, se produce el despliegue de la dinámica conflictiva pulsional más allá del ser humano, a la totalidad de lo viviente. ${ }^{75}$

En ambos casos, a través de la imposición de perspectiva se asiste a un empoderamiento del sujeto. Espacialmente, a la ampliación yoica y a la coordinación de las partes del viviente corresponden mayor capacidad de manejo y autonomía respecto a la realidad exterior, y mayor capacidad de incorporación de exterior. Ampliar el interior en una determinada dirección y sentido —el yo, la coordinación- es ampliar la capacidad para con el exterior. Desde este punto de vista, a lo que tiende la vida saludable en ambos casos es a un saber hacer, a un quehacer con el conflicto; el empoderamiento del yo permite un mejor manejo del conflicto con las diversas instancias, psíquicas y no; perder el carácter enfermo y empobrecido de la vida es terminar en lo posible con el conflicto interno, y ser capaz de aplicarse activamente al externo. El psicoanálisis y la vida ascendente juegan ambos en el campo del riesgo y del conflicto — más allá del placer y el displacerbuscando el empoderamiento como capacidad de poder-hacer.

A través del análisis espacial del despliegue de la vida en términos del riesgo y el conflicto ha sido posible dar cuenta del paso de una dinámica en donde lo que se busca es escapar o elidir a los mismos, a una disposición en la cual lo conflictivo resulta el centro mismo de la vida y, por ende, la propia disposición vital ha de necesariamente pasar por un saber actuar en relación a dicho conflicto. Si bien desde una matriz diversa, producto de distintas concepciones vitales, ${ }^{76}$ la tendencia respecto al sujeto tanto para Nietzsche como

\footnotetext{
${ }^{74}$ Freud, El malestar, 118.

75 "El yo obedece, simplemente, a la puesta en guardia del principio de placer" (Freud, El yo y el ello, 58). Por esta correlación marcada por Freud, se sigue como corolario que un más allá del principio del placer implique un más allá de la función yoica $-\mathrm{y}$ por ende, permita válidamente extender la dinámica conflictiva ErosTánatos a la vida en general (como hace notar Guillaumin, el término 'Tánatos' no es empleado por Freud, sino que aparece en un texto de 1930 de W. Steckel, Der Wille zum Leben (Leipzig, Wendepunktverlag) (Cfr. Jean Guillaumin, 'La pulsion de mort, prothèse théorique de l' impensé de contre transfert dans le psychanalyse?', Revue Française de Psychanalyse, 'La pulsion de mort', tomo III (Marzo-Abril de 1989) París, PUF, 528-541, 535)).

${ }^{76} \mathrm{Al}$ respecto $c f r$. Alonso Zengotita, 'Derivas sociopolíticas de la conservación y la expansión: la vida misma en Nietzsche y Freud', Revista de Estudios Avanzados, Universidad de Santiago de Chile, núm. 20 (diciembre, 2013): 75-95.
} 
para Freud implicará la búsqueda de un empoderamiento vía confrontación con el conflicto. Nietzsche mantiene respecto a las tipologías de la vida descendente: "quieren tranquilidad, paz frente a sus afectos [...]. Otros quieren tranquilidad hacia el exterior, una vida sin peligro, quisieran no ser envidiados y ser atacados $[\ldots] " .{ }^{77}$ Freud establece:

Hemos manifestado la inequívoca tendencia a hacer a un lado la muerte, a eliminarla de la vida. Hemos intentado matarla con el silencio [...] Esta actitud cultural-convencional hacia la muerte se completa con nuestro total descalabro cuando fenece una de las personas que nos son próximas [...] Ahora bien, esta actitud frente a la muerte tiene un fuerte efecto sobre nuestra vida. La vida se empobrece, pierde interés, cuando la máxima apuesta en el juego de la vida, que es la vida misma, no puede arriesgarse. Se vuelve tan insípida e insustancial como un flirt norteamericano, en que de antemano se ha establecido que nada puede suceder $[\ldots]$. $^{78}$

Tanto en Nietzsche como en Freud existe una valoración determinada de la vida en términos de la capacidad de hacer frente al riesgo y al conflicto: el empoderamiento que implica el enfrentar y no elidir dicho conflicto, dado desde el psicoanálisis y la Wille zur Macht, adquiere así profunda significación ética. Al ser abordada en términos estructurales, la trama del conflicto y el riesgo no implica un aspecto lateral en las obras de Freud y Nietzsche, sino un fundamento específico de la dinámica vital.

\footnotetext{
${ }^{77}$ Nietzsche, Fragmentos, 1 [104], 59. Resulta interesante notar la completa inversión respecto a lo dispuesto en El nacimiento de la tragedia; frente a esto, define ahora respecto de la ascendente: "Esta 'audacia' de las razas nobles, que se manifiesta de manera loca, absurda, repentina, ese elemento imprevisible e incluso inverosímil de sus empresas [...] y su desprecio por la seguridad”. Friedrich Nietzsche, Genealogía de la moral (Madrid: Alianza, 2000), 55.

${ }^{78}$ Sigmund Freud, "De guerra y de muerte", en Obras completas, tomo XIV, 290-291.
} 


\section{Bibliografía}

Almeida, Rogelio. Nietzsche e Freud, eterno retorno e compulsão à repetição. São Paulo: Loyola, 2005.

Ansell-Pearson, Keith. Nietzsche and Modern German Thought. Londres: Routledge, 1991. Assoun, Paul Laurent. Freud et Nietzsche. París: P.U.F., 2008.

Boothby, Richard. Freud as Philosopher, Metapsychology after Lacan. Londres: Routledge, 2001.

Brenner, Charles. "Aspects of Psychoanalytic Theory: Drives, Defence and the PleasureUnpleasure Principle”. Psychoanalytic Quarterly, 77 (2008): 707-717.

Butler, Judith. Mecanismos psíquicos del poder. Madrid: Cátedra, 2010.

Calder, William. "El debate Wilamowitz-Nietzsche: nuevos documentos y una reevaluación”. Nietzsche-Studien, 12 (1983): 214-254.

Couvreur, Catherine. "Une équation à deux inconnues". Revue Française de Psychanalyse, 'La pulsion de mort', tomo III (marzo-abril, 1989): 642-668.

Chapelle, David. Nietzsche and Psychoanalysis. Albany: State University of New York Press, 1993.

Drivet, Leandro. "Freud como lector de Nietzsche. La influencia de Nietzsche en la obra de Freud”. Civilizar, 15, núm. 29 (2015): 197-214.

Faulkner, James. “The Body As Text In The Writings of Nietzsche And Freud”. Minerva, 6 (2003): 94-124.

Fernández García, Eugenio. "En torno al malestar: aproximaciones de Nietzsche y Freud”. Mal-Estar Subjetivo, 1, núm. 1 (2001): 10-42.

Freud, Sigmund. Proyecto de psicología. En Obras completas, tomo I. Buenos Aires: Amorrortu, 1992.

Freud, Sigmund. Tres ensayos de teoría sexual. En Obras completas, tomo VII. Buenos Aires: Amorrortu, 1992.

Freud, Sigmund. Análisis de la fobia de un niño de cinco años. En Obras completas, tomo X. Buenos Aires: Amorrortu, 1992.

Freud, Sigmund. "La perturbación psicógena de la visión según el psicoanálisis”. En Obras completas, tomo XI. Buenos Aires: Amorrortu, 1992. 
Freud, Sigmund. Pulsiones y destinos de pulsión. En Obras completas, tomo XIV. Buenos Aires: Amorrortu, 1992.

Freud, Sigmund. "De guerra y de muerte". En Obras completas, tomo XIV. Buenos Aires: Amorrortu, 1992.

Freud, Sigmund. Más allá del principio del placer. En Obras completas, tomo XVIII. Buenos Aires: Amorrortu, 1992.

Freud, Sigmund. El yo y el ello. En Obras completas, tomo XIX. Buenos Aires: Amorrortu, 1992.

Freud, Sigmund. El malestar en la cultura. En Obras completas, tomo XXI. Buenos Aires: Amorrortu, 1992.

Freud, Sigmund. "Análisis terminable e interminable”. En Obras completas, tomo XXIII. Buenos Aires: Amorrortu, 1992.

Gasser, Reinhard. Nietzsche und Freud. Berlín: De Gruyter, 1997.

Golomb, Jacob, Weaver Santaniello y Ronald Lehrer. Nietzsche and Depth Psychology. Nueva York: State University of New York Press, 1999.

Granier, Jean. "Le statut de la philosophie selon Nietzsche et Freud". Nietzsche-Studien, núm. 8 (1979): 210-224.

Guillaumin, Jean. 'La pulsion de mort, prothèse théorique de l' impensé de contre transfert dans le psychanalyse?". Revue Française de Psychanalyse, 'La pulsion de mort', tomo III (marzo-abril, 1989): 528-541.

Hanza, Karl. "Nec docere neque delectare sed sublimare. Sobre la metáfora de laliteratura como sublimación en Freud y Nietzsche”. Estudios de filosofía, 28 (2003): 35-54.

Lacan, Jacques. "Clase 12: la sexualidad en los desfiladeros del significante". En El seminario. Libro 11: Los cuatro conceptos fundamentales del psicoanálisis. Madrid: Paidós, 2003.

Lévy Lazcano, Silvia. "Freud y Nietzsche: crónica de un desencuentro". Historia Autónoma, 3 (2013): 63-76.

Nietzsche, Friedrich. Aurora. Barcelona: Alba, 1999.

Nietzsche, Friedrich. Genealogía de la moral. Madrid: Alianza, 2000.

Nietzsche, Friedrich. La ciencia jovial. Madrid: Biblioteca Nueva, 2001.

Nietzsche, Friedrich. El nacimiento de la tragedia. Madrid: Alianza, 2007. 
Nietzsche, Friedrich. Humano, demasiado humano. Madrid: Akal, 2007.

Nietzsche, Friedrich. Así habló Zarathustra. Madrid: Alianza, 2007.

Nietzsche, Friedrich. El crepúsculo de los ídolos. Madrid: Alianza, 2007.

Nietzsche, Friedrich. Fragmentos póstumos, vol. IV. Madrid: Tecnos, 2008.

Nietzsche, Friedrich. Correspondencia VI (octubre 1887-enero 1889). Madrid: Trotta, 2012.

Onfray, Michael. Nietzsche contra Freud. Madrid: Taurus, 2012.

Reginster, Bernard. The Affirmation of Life: Nietzsche on Overcoming Nihilism. Cambridge, MA: Harvard University Press, 2006.

Rozitchner, León. Freud y el problema del poder. México: Folios, 1982.

Sokel, William. “On the Dionysian in Nietzsche”. New Literary History, 36, núm. 4 (2005): 501-520.

Steineger, Jean. "Friedrich Nietzsche and Sigmund Freud Failure: A Tomist Protest on Truth”. Quodlibet Diary, 6, núm. 1 (2004): 23-38.

Sweet, Denis. "The Birth of 'The Birth of Tragedy"'. Journal of the History of Ideas, 60, núm. 2 (1999): 345-359.

Uribe, Darío. Vitalismo cósmico. Bogotá: Siglo del Hombre, 2002.

Vázquez Rocca, Adolfo. "La influencia de Nietzsche sobre Freud". Arjé. Revista de Cultura y Ciencias Sociales, núm. 4 (2005): 22-36.

Vázquez Rocca, Adolfo. "Nietzsche y Freud, negociación, culpa y crueldad: las pulsiones y sus destinos, 'eros' y 'thanatos' (agresividad y destructividad)”. Eikasia, núm. 57 (2014): 67-97.

Weinberg, Kurt. "Nietzsche's Paradox of Tragedy”. Yale French Studies, núm. 96 (1999): 86-99.

Zengotita, Alonso. "Derivas sociopolíticas de la conservación y la expansión: la vida misma en Nietzsche y Freud". Revista de Estudios Avanzados, núm. 20 (diciembre, 2013): 75-95. 